\title{
AVALIAÇÃO DA DOR COMO INSTRUMENTO PARA O CUIDAR DE RECÉM- NASCIDOS PRÉ-TERMO ${ }^{1}$ \\ PAIN EVALUATION AS A CARE INSTRUMENT IN PREMATURE NEWBORNS EVALUACIÓN DEL DOLOR COMO INSTRUMENTO PARA EL CUIDADO DE LOS RECIÉN NACIDOS PREMATUROS
}

\author{
Bruna Bryenna Brito Sousa², Marinese Herminia Santos', Francisca Georgina Macêdo de Sousa ${ }^{4}$, Anna Paula Ferrario \\ Gonçalves', Sirliane de Souza Paiva ${ }^{6}$
}

${ }^{1}$ Trabalho apresentado no $3^{\circ}$ Seminário Internacional de Filosofia e Saúde, Florianópolis, outubro de 2006.

${ }^{2}$ Enfermeira do Programa Saúde da Família do município de Barreirinhas, MA. Membro do Grupo de Estudo e Pesquisa na Saúde da Criança e do Adolescente (GEPSCA) na Universidade Federal do Maranhão (UFMA). Maranhão, Brasil.

${ }^{3}$ Enfermeira. Mestre em Ciências da Saúde. Docente do Curso de Enfermagem da UFMA. Membro do GEPSCA. Maranhão, Brasil.

${ }^{4}$ Enfermeira. Mestre em Enfermagem. Docente do Curso de Enfermagem da UFMA. Doutoranda do Programa de Pós-Graduação em Enfermagem (PEN) da Universidade Federal de Santa Catarina (UFSC). Membro do GEPSCA. Maranhão, Brasil.

${ }^{5}$ Enfermeira. Doutora em Enfermagem. Docente do Curso de Enfermagem da UFMA. Membro do GEPSCA. Maranhão, Brasil.

${ }^{6}$ Enfermeira. Doutora em Enfermagem. Docente do Curso de Enfermagem da UFMA. Maranhão, Brasil.

PALAVRAS-CHAVE: Enfermagem neonatal. Prematuro. Medição da dor.

KEYWORDS: Neonatal nursing. Premature infant. Pain measurement.

PALABRAS CLAVE: Enfermería neonatal. Prematuro. Dimensión del dolor.
RESUMO: A dificuldade de avaliar e mensurar a dor no recém-nascido pré-termo constitui obstáculo ao cuidado em Unidade de Terapia Intensiva Neonatal. Com este desafio desenvolveu-se a proposta do estudo, centrando-o na identificação da dor em recém-nascidos prematuros, utilizando a mímica facial. Os objetivos foram: analisar como mães e enfermeiras identificam a dor em recém-nascidos prematuros e verificar se identificam os sinais de dor pela expressão facial. Trata-se de estudo exploratório-descritivo envolvendo 24 mães e 12 enfermeiras como sujeitos do estudo. Para a coleta de dados utilizou-se a entrevista semi-estruturada e um quadro com seis fotos de recém-nascidos avaliadas pelo Sistema de Codificação da Atividade Facial Neonatal. Conclui-se que as mães identificaram melhor a dor pela expressão facial do que as enfermeiras. A avaliação da dor deve ser preocupação da enfermeira, pois para o cuidado, aspectos como identificação de sinais álgicos e sua caracterização são ferramentas para o cuidado ao recém-nascido prematuro.

ABSTRACT: The difficulty of evaluating and measuring pain in a premature newborn constitutes as an obstacle to care in the Neonatal Intensive Care Unit. In response to this challenge, we developed the proposal of this study, centered on the identification of pain in premature newborns through the utilization of facial mimicry. The objectives of this study were to analyze how mothers and nurses identify the pain of premature newborns and to verify the capacity of nurses and mothers in identifying the signs of pain through facial expressions. This exploratory descriptive study involved 24 mothers and 12 nurses. In order to collect the data we utilized a questionnaire with open, as well as closed, questions and a collage of six photos of newborns as evaluated by the Neonatal Facial Coding System. We conclude that mothers better identify pain through facial expressions in comparison with nurses. Pain evaluation should be a concern of the nurse, for in order to provide care, aspects such as identifying this signs and their characterizations are instruments of care for the premature newborn.

RESUMEN: La dificultad de evaluar y medir el dolor en el recién nacido prematuro se constituye en un obstáculo al cuidado en la Unidad de Terapia Intensiva Neonatal. A partir de este desafío desarrollamos la propuesta del presente estudio, centrándola en la identificación del dolor en los recién nacidos prematuros, utilizando para ello la mímica facial. Los objetivos fueron los siguientes: analizar cómo las madres y las enfermeras identifican el dolor en los recién nacidos prematuros; verificar la capacidad de los enfermeros y las madres de identificar las señales del dolor por la expresión facial. Se trata de un estudio exploratorio descriptivo del cual participaron 24 madres y 12 enfermeras. Para la recolección de los datos se utilizó un cuestionario con preguntas abiertas y cerradas y un cuadro con seis fotos de recién nacidos evaluados por el Sistema de Codificación de la Actividad Facial Neonatal. Se concluye que las madres identificaron mejor el dolor por la expresión facial que las enfermeras. La evaluación del dolor debe ser preocupación de la enfermera, ya que para el cuidado, aspectos como la identificación de señales dolorosas y su caracterización son herramientas para el cuidado del recién nacido prematuro.
Endereço: Francisca Georgina Macêdo de Sousa R. dos Sabiás, Quadra 7, No 12, Ed. Porto Alegre, Ap. 1004 65.075-360 - Renascença II, São Luis, MA, Brasil.

E-mail: fgeorginams@hotmail.com
Artigo original: Pesquisa

Recebido em: 25/10/2006

Aprovação final: 24/04/2007 


\section{INTRODUÇÃO}

A percepção da dor é uma qualidade inerente à vida, no entanto, a capacidade para a percepção de uma condição dolorosa não depende de uma experiência anterior, pois a dor é uma sensação primária própria, assim como o tato, o olfato, a visão e a audição, essenciais para o crescimento e o desenvolvimento do indivíduo. ${ }^{1}$ No que diz respeito ao recém-nascido $(\mathrm{RN})$, a dor não foi motivo de preocupação de clínicos e investigadores durante muito tempo, pois existia a crença de que o neonato era incapaz de sentir dor. Atualmente, no entanto, pesquisas têm documentado que o neonato possui todos os componentes funcionais e neuroquímicos necessários para a recepção e transmissão do estímulo doloroso. ${ }^{2}$

A suspeita de que o RN era capaz de sentir dor iniciou na década de 1960, quando foi possível observar que a mielinização não era imprescindível para a transmissão dos impulsos pelo trato sensorial. Hoje, sabe-se que os elementos do sistema nervoso central, necessários para a transmissão do estímulo doloroso ao córtex cerebral estão presentes em recém-nascidos a termo e em prematuros, embora a maturação e a organização desse sistema neurosensorial continue durante a vida pós-natal. ${ }^{3}$

A dor foi conceituada em 1986 pela Associação Internacional para o Estudo da Dor (IASP), como uma experiência sensorial e emocional desagradável, associada a lesões reais ou potenciais. Esse conceito desconsidera a dor e o desconforto de pacientes que ainda não possuem condições verbais de expor o que sentem, como por exemplo, os recém-nascidos (RNs). Porém, já se tem conhecimento que, além de serem sensíveis a dor, os RNs podem sofrer conseqüências orgânicas e emocionais e comprometer o seu crescimento e o seu desenvolvimento. ${ }^{4} \mathrm{Nas}$ últimas décadas, houve muitos avanços no cuidado ao RN, porém a avaliação e o manejo da dor ainda não têm merecido a devida atenção nas Unidades de Terapia Intensiva Neonatal (UTINs). Os recursos tecnológicos de alta complexidade utilizadas nesses serviços têm imprimido uma característica ímpar na assistência aos bebês de risco, principalmente aos $\mathrm{RNs}$ prematuros, e, contribuído significativamente para a redução da mortalidade neonatal. Mas, é nesse ambiente que os RNs são comumente expostos a múltiplos eventos estressantes e dolorosos. ${ }^{5} \mathrm{Calcu}$ la-se que, como parte dos cuidados de rotina nas UTINs, cada RN gravemente doente seja submetido a cerca de 50 a 150 procedimentos dolorosos por dia. ${ }^{6}$ Por isso, torna-se imprescindível saber avaliar a dor e estabelecer adequada intervenção, no sentido de diminuir e/ou evitar efeitos nocivos para o desenvolvimento do $\mathrm{RN}$, além de contribuir para uma recuperação mais rápida e para a qualidade da assistência prestada. O que, talvez, se oponha para que isso aconteça seja a dificuldade de avaliação do fenômeno doloroso no RN, considerando ser a interpretação da dor algo subjetivo e abstrato.

Devido à impossibilidade de qualquer tipo de verbalização, a principal forma de expressar a dor em RN passa a ser por atitudes comportamentais. ${ }^{7}$ Dessa forma, fica subentendido que a avaliação da dor em Recém-Nascido Pré-Termo (RNPT) fundamenta-se na avaliação das respostas destes à dor. Essas respostas podem ser analisadas a partir de alterações das medidas fisiológicas e comportamentais observadas antes, durante e depois de um estímulo potencialmente doloroso. ${ }^{3}$ Entretanto, avaliar tais alterações é, por vezes, difícil, pois os indicadores observáveis da dor podem ser mínimos ou ausentes, o que exige dos profissionais adequar a forma, a linguagem e o conteúdo da prática de avaliação da dor no sentido de atender a realidade dos usuários e principalmente dos grupos especiais. ${ }^{8}$ Assim, foram desenvolvidas escalas multidimensionais, que tentam analisar respostas comportamentais associadas a algumas respostas fisiológicas à dor. Dentre as várias escalas de dor descritas, as mais estudadas são o Sistema de Codificação da Atividade Facial (SCAFN), a Escala de Avaliação de Dor (NIPS) e o Perfil de Dor do Prematuro (PIPP). ${ }^{6}$

A avaliação comportamental da dor baseia-se na alteração de determinadas expressões comportamentais após um estímulo doloroso, parecendo ser mais sensível e específico na detecção da dor quando comparada às medidas fisiológicas. ${ }^{7}$ Dentre os comportamentos que podem indicar dor no RN estão o choro, a expressão facial e a agitação. Entre as reações fisiológicas, destacam-se o aumento da freqüência cardíaca, respiratória e da pressão arterial, a diminuição da saturação de oxigênio, a apnéia, a cianose, os tremores e a sudorese. ${ }^{7}$ Entre as respostas comportamentais à dor as mais estudadas são a resposta motora, a mímica facial, o choro e o padrão de sono e vigília."

A dor acarreta importantes repercussões no RN, das quais se enfatiza o desenvolvimento cerebral prejudicado, o que ameaça a sua estabi- 
lidade fisiológica e ocasiona reflexos negativos, como problemas comportamentais, que serão percebidos apenas na infância. ${ }^{9}$ São citadas ainda como conseqüências da dor os problemas psiquiátricos, tais como ansiedade, depressão e esquizofrenia. Além das conseqüências já referidas, a dor desencadeia um aspecto negativo no quadro clínico do $\mathrm{RN}$, o que justifica a necessidade do enfermeiro avaliar, prescrever e realizar cuidados complementares ao alívio da dor. ${ }^{9}$

Tendo-se como premissa que ao cuidar de RNs devem ser consideradas as situações de desconforto e de dor por eles vivenciadas é que esta condição foi selecionada como objeto para este estudo. No entanto, a dor ainda se constitui em um desafio tanto para a pesquisa como para o cuidado de enfermagem e de saúde. Considera-se que a busca de conhecimentos e o desenvolvimento de estudos sobre a temática caracterizam-se como instrumentos para uma nova prática em neonatologia. Foi com esse desafio que a proposta do estudo foi desenvolvida, centrando-a na identificação da dor em RNPT pelas mães e enfermeiras.

\section{OBJETIVOS}

Analisar como enfermeiras e mães identificam a dor em RNPT e se o fazem pela expressão facial; verificar se as enfermeiras e as mães reconhecem os sinais sugestivos de dor pela expressão facial do RNPT.

\section{METODOLOGIA}

Estudo exploratório e descritivo sobre a perspectiva de reconhecimento da dor como um sinal vital pela expressão facial do RNPT. Os sujeitos foram 24 mães de RNPT internados na UTI Neonatal de um Hospital Universitário e 12 enfermeiras da referida unidade. $\mathrm{O}$ estudo foi realizado de março a maio de 2005 , tendo como instrumentos para a coleta de dados dois questionários: um para as enfermeiras - com 10 perguntas entre abertas e fechadas; e o outro para as mães com oito perguntas com as mesmas características (Apêndices 1 e 2). Para avaliar a capacidade dos sujeitos do estudo em avaliar os sinais de dor foi utilizado um quadro com seis (06) fotos de RNPT (Apêndice 3).

A pesquisa foi desenvolvida em quatro etapas. A primeira correspondeu a todo o processo que envolve Pesquisa com Seres Humanos e aos aspectos burocráticos de autorização do hospital e da unidade para a realização do estudo. Nessa etapa foram explicados os objetivos e o processo metodológico do estudo, solicitado e obtido o Termo de Consentimento Livre e Esclarecido dos envolvidos. Às mães, foi solicitado autorização por escrito para a realização e utilização das imagens fotográficas das crianças no estudo. A referida etapa foi precedida pela aprovação do projeto pelo Comitê de Ética em Pesquisa do Hospital Universitário (HU) da Universidade Federal do Maranhão (UFMA) registrado sob o N³3104-098/2005.

A segunda etapa compreendeu a tomada fotográfica das crianças em máquina digital sem a utilização de flash, pois a incidência de um estímulo luminoso poderia alterar a mímica facial do RN. Foram selecionados dois RNPT cujos critérios foram: idade gestacional inferior a 37 semanas, que estivessem internados na UTI Neonatal há cinco dias ou mais, acompanhados pelas mães e sem suporte mecânico de ventilação. Para a tomada fotográfica foi aplicado o SCAFN, ${ }^{10}$ com vistas a identificar e fotografar o momento real de dor expressa pelo RN. Os RNs foram fotografados em diferentes momentos, incluindo aqueles que envolviam procedimentos médicos e de enfermagem, e, os de sono e repouso, para em seguida serem impressas em papel fotográfico para a visualização das imagens.

O SCAFN avalia as alterações dos movimentos faciais frente a um estímulo doloroso levando em conta a presença ou ausência dos seguintes movimentos faciais: fronte saliente; olhos espremidos; sulco naso-labial aprofundado; lábios entreabertos; boca esticada; lábios franzidos; língua tensa, protrusa e esticada e tremor do queixo. ${ }^{10}$ Para cada um dos itens, quando presente, é atribuído um (01) ponto, sendo o escore máximo de oito (08) pontos. Considera-se a presença de dor quando a pontuação é superior a dois. ${ }^{10}$ Desses sinais, a fronte saliente, os olhos espremidos, o sulco nasolabial aprofundado e os lábios entreabertos estão presentes em mais de $90 \%$ dos RNs submetidos a um estímulo doloroso e em menos de $50 \%$ dos que recebem um estímulo desagradável, porém não doloroso. ${ }^{7}$ O SCAFN permite a observação da expressão facial de forma não invasiva e constitui um dos pontos mais importantes para o estudo da expressão da dor no RN. ${ }^{7}$

A terceira etapa compreendeu cuidadosa observação e análise das fotos. Para tanto, utilizou-se do SCAFN e dos registros feitos em um bloco pelas 
pesquisadoras, em que eram descritas as circunstâncias e situações do momento da tomada fotográfica. Completada a fase de realização das fotos, seguiuse a escolha da série de fotos que apresentasse os critérios para cumprir os objetivos do estudo: boa iluminação, ou seja, todas as fotos deveriam apresentar as nuances da imagem focalizada, como brilho e contraste, além de exibir uma variedade de tons e cores; nitidez da face do neonato, isto é, nenhuma das fotos da série deveria apresentar imagens com duplo contorno, desfocadas e/ou tremidas; e que pelo menos uma delas deveria caracterizar expressão facial de dor no momento de um estímulo doloroso. Do total, foram selecionadas seis fotos e, em seguida, organizadas em um quadro de madeira com dimensões de $40 \times 40 \mathrm{~cm}$. As fotos foram dispostas em duas colunas, com três fotos cada, numeradas em algarismos romanos. A foto I corresponde a um bocejo da criança; a II a uma expressão de desconforto causado por ruído excessivo; a III a expressão de desconforto causado pela fricção do calcanhar pela enfermeira; a V corresponde a um momento de repouso e a VI a desconforto causado por iluminação excessiva. De todas, a IV fotografia, foi a que melhor caracterizou a expressão de dor na criança e apresentou os seguintes comportamentos faciais: fronte saliente, olhos espremidos, sulco naso-labial aprofundado, boca estirada, lábios entreabertos e língua tensa obtendo um escore de seis pontos, o suficiente para o SCAFN classificar a situação como um momento real de dor (Apêndice 3).

$\mathrm{Na}$ quarta etapa foi realizada entrevista com os dois grupos (mães e enfermeiras) e a apresentação do quadro de fotos para que assim fosse possível alcançar os objetivos definidos no estudo.

\section{RESULTADOS}

Em relação à capacidade do RNPT sentir dor, houve unanimidade entre as enfermeiras em considerar que o paciente nessa faixa etária sente dor. Este resultado mostra como a concepção de dor nos RNs vem mudando, pois até o final da década de 70 , prevalecia a idéia de que o RNPT não possuía seu sistema nervoso completamente desenvolvido e, dessa forma, não havia sensibilidade dolorosa. ${ }^{12}$ Entre as mães, observou-se que apenas uma não concordou que o RNPT sinta dor, podendo-se inferir que este fato seja justificado em decorrência da pouca idade materna (14 anos).
O que diz respeito ao conhecimento sobre os instrumentos/escalas de avaliação da dor no RN, observou-se que, do total de enfermeiras, $25,0 \%$ delas referiram possuir conhecimento sobre algum tipo de escala para avaliação da dor em RNPT, no entanto, não souberam identificar o nome da mesma. De modo semelhante, em um outro estudo realizado, apenas um terço dos entrevistados referiram conhecer alguma escala para avaliação da dor. ${ }^{11}$ Esse fato é preocupante, visto que, as escalas de avaliação da dor no RN foram elaboradas desde o final da década de 80,2 além de que, desconhecer os instrumentos de avaliação da dor pode dificultar a sua identificação assim como o emprego de condutas adequadas que a minimizem.

Das enfermeiras e mães, quando questionadas sobre as características de um RNPT com dor, $95,7 \%$ citaram alterações comportamentais, enquanto 4,3\% não souberam responder. Entre as alterações comportamentais mais citadas pelas mães estava o choro com $73,9 \%$, os movimentos de membros $(34,8 \%)$ e $26,1 \%$ referiram outras alterações como recusa do peito e careta. Quanto às enfermeiras, 75,0\% citaram alterações comportamentais e $25,0 \%$ alterações comportamentais associadas a alterações fisiológicas. As alterações comportamentais mais citadas foram: choro $(83,3 \%)$, movimentos de membros $(83,3 \%)$, fronte saliente $(41,7 \%)$, careta $(41,7 \%)$, gemência $(25,0 \%)$, boca aberta $(16,7 \%)$, olhos espremidos $(16,7 \%)$ e sulco naso-labial aprofundado (8,3\%). Entre as alterações fisiológicas referidas pelas enfermeiras encontrou-se a diminuição da saturação de oxigênio e aumento dos batimentos cardíacos com $16,7 \%$, respectivamente, enquanto que $8,3 \%$ referiram a mudança de cor da pele e a dispnéia.

As mudanças comportamentais do $\mathrm{RN}$ foram facilmente identificadas pelos dois grupos, fato importante no cuidado a esta faixa etária, definida como pré-verbal, o que poderá facilitar, no futuro, a utilização do SCAFN como instrumento de avaliação da dor.

Quando perguntadas sobre a importância de tratar a dor no RNPT, 95,7\% das mães responderam positivamente. Destas, $50,0 \%$ justificaram sua afirmação alegando que, quando a dor é tratada, há uma diminuição do sofrimento da criança; $27,0 \%$ achavam que o tratamento da dor proporciona conforto e tranqüilidade à criança; $18,2 \%$ afirmaram que a recuperação da criança acontece 
de forma mais rápida e 4,5\% não foi capaz de justificar sua opção.

Entre as enfermeiras, $100 \%$ consideraram importante o tratamento da dor e justificaram sua opção com as seguintes respostas: diminui o sofrimento do $\mathrm{RN}$ (50,0\%); proporciona conforto $(16,7 \%)$; proporciona recuperação mais rápida do RN (8,3\%); e que a dor não tratada concorre para conseqüências psicológicas na criança $(8,3 \%)$. Mesmo concordando com a importância do tratamento da dor $8,3 \%$ das enfermeiras não justificaram sua resposta.

Ao analisar as atitudes relatadas por mães e enfermeiras diante do RNPT com dor, verificou-se que $52,1 \%$ das mães relataram fazer carinho em seus filhos colocando-os nos braços e na posição canguru, enquanto que, $58,3 \%$ das enfermeiras atuam com intervenções como a sucção não nutritiva, o uso de glicose e a administração de analgésicos prescritos.

Considerando que a unidade neonatal em que foi realizada a pesquisa é referência para o Ministério da Saúde em Assistência Humanizada ao RecémNascido de Baixo Peso - Método Canguru, ${ }^{12}$ os profissionais são capacitados para orientar as mães quanto à necessidade de oferecerem aos seus bebês carinho além de apoiarem para a formação do apego entre mãe e filho. $O$ contato físico entre mãe e filho, contato pele a pele, durante procedimentos médicos e de enfermagem, tem se mostrado eficaz para diminuir a dor no RN.?

Nesse sentido é importante enfatizar que o tratamento da dor inicia-se pelas ações e atitudes de humanização das UTIs, pela redução do ruído e da luz, pelos protocolos de intervenção mínima do $\mathrm{RN}$, pela abordagem não farmacológica da dor e alcança a terapêutica analgésica ou anestésica. ${ }^{2} \mathrm{O}$ carinho, assim como as medidas não farmacológicas, devem fazer parte da rotina das UTINs, cabendo à enfermeira promovê-las por meio da capacitação da equipe e do fazer cotidiano.

Em relação às situações nas quais se costumava utilizar analgesia, verificou-se nas respostas das enfermeiras que $75,0 \%$ citaram apenas procedimentos realizados por médicos, podendo significar que não consideram dolorosos os procedimentos de enfermagem. Um dado interessante observado é que, apesar das enfermeiras não citarem os procedimentos de enfermagem como dolorosos, 58,3\% delas adotam intervenções não farmacológicas como citadas anteriormente.
Tabela 1 - Distribuição das respostas de mães e enfermeiras de uma UTI Neonatal, quanto à identificação da foto da face de dor do RNPT. São Luís - MA, 2005.

\begin{tabular}{lcccc}
\hline Face com expressão & \multicolumn{2}{c}{ Mães } & \multicolumn{2}{c}{ Enfermeiras } \\
de dor & $\mathbf{n}$ & $\mathbf{\%}$ & $\mathbf{n}$ & $\mathbf{\%}$ \\
\hline Foto I & - & - & 1 & 8,3 \\
Foto II & 2 & 8,7 & 1 & 8,3 \\
Foto III & 4 & 17,4 & 5 & 41,7 \\
Foto IV & 15 & 65,2 & 5 & 41,7 \\
Foto V & - & - & - & - \\
Foto VI & 2 & 8,7 & - & - \\
\hline Total & $\mathbf{2 3}$ & $\mathbf{1 0 0 , 0}$ & $\mathbf{1 2}$ & $\mathbf{1 0 0 , 0}$ \\
\hline
\end{tabular}

Quanto à identificação da face de dor, verifica-se na Tabela 1 que 65,2 \% das mães e 41,7\% das enfermeiras reconheceram adequadamente a foto indicativa de dor (Foto IV). No entanto, as mães foram capazes de identificar melhor os sinais de dor do que as enfermeiras. Os pais são os que melhor observam e informam aos profissionais de saúde a respeito das alterações comportamentais que possam estar ocorrendo com seus filhos, o que possivelmente se justifica devido ao seu contato íntimo e pessoal com a criança. ${ }^{12}$ Segundo o autor a avaliação comportamental da criança, realizada pelos pais, é muitas vezes mais acurada que a de médicos e enfermeiros. Quando perguntado o motivo pelo qual escolheram a foto número IV, $100,0 \%$ das mães e das enfermeiras relataram ter sido a expressão do rosto.

Observa-se que $17,4 \%$ das mães e $41,7 \%$ das enfermeiras indicaram a foto número III, na qual o RN expressa desconforto por fricção do calcanhar, como sendo a foto de expressão de dor. Das mães, $17,2 \%$ escolheram foto II e VI, que expressam desconforto causado por ruído e iluminação excessiva respectivamente. Entre as enfermeiras, $8,3 \%$ indicaram a foto I que representa um bocejo e $8,3 \%$, optaram pela II, que expressa desconforto causado por ruído. As alterações da mímica facial constituem um dos eixos fundamentais no estudo da expressão de dor em RNs. Várias pesquisas têm indicado que a observação da expressão facial parece ser um método sensível específico, e útil para a avaliação da dor em recém-nascido a termo e pré-termo, pois além de não invasiva, é efetiva 
e universal, tanto por adultos treinados na sua decodificação como por indivíduos não treinados que são responsáveis pelos cuidados diários do neonato, como enfermeiras e pais. ${ }^{1,5-6,13}$ Aliada a estas questões, a avaliação facial de crianças pré-verbais é expressiva e pode informar ao observador, além da dor, o estado emocional do neonato. ${ }^{13}$

Durante as entrevistas constatou-se que uma grande parte das enfermeiras pesquisadas, mostrava-se desconfiada e insegura com as questões do instrumento de coleta de dados. Pode-se inferir que este fato tenha ocorrido por sentirem uma responsabilidade maior em identificar a foto correspondente à face de dor, como se isso fosse influenciar em sua qualidade profissional. Isso pode ter influenciado no maior número de "erros" por parte desse grupo.

Quanto ao tempo de experiência em neonatologia, verificou-se que as enfermeiras que possuíam mais de nove anos de serviço, não conseguiram identificar a face do RNPT com dor. A experiência profissional, o conhecimento teórico e o reconhecimento da dor de pacientes são fatores controversos, apresentando resultados diferentes em diversos trabalhos. Para alguns, a experiência profissional não exerce qualquer influência na interpretação da dor do paciente feita pelo profissional de saúde ${ }^{13}$ e que o maior conhecimento teórico, a maior bagagem educacional, a experiência profissional mais intensa e o convívio mais próximo com a dor de pacientes podem, conjuntamente, dificultar a percepção da equipe de enfermagem quanto ao reconhecimento da dor no RN. ${ }^{1}$ Ao contrário, outros estudos, ${ }^{14}$ mostram que os profissionais de saúde com maior conhecimento teórico e com maior experiência profissional são mais sensíveis em termos de reconhecimento da intensidade da dor.

Observou-se nesta pesquisa que as mães primíparas obtiveram maior êxito na identificação $\mathrm{da}$ foto correspondente a face de um RNPT com dor. Entretanto, alguns estudos demonstram que o fato de ter ou não filhos não exerce qualquer influência no reconhecimento da dor expressa por indivíduos adultos. ${ }^{14}$

Seria possível tecer outras discussões sobre esses dois últimos aspectos se a proposta fosse um estudo analítico e de associação estatística das variáveis, o que não foi o caso. Fica aqui um vazio que poderá ser preenchido por outras pesquisas.

\section{CONCLUSÕES}

A dor como um sinal subjetivo, acrescida da impossibilidade do RN verbalizá-la, condiciona o profissional de saúde em Unidade de Terapia Intensiva Neonatal a estar atento às alterações comportamentais e fisiológicas que acompanham o episódio doloroso, além de apontar para a necessidade da utilização de instrumentos de avaliação para mensuração da dor nessa faixa etária.

Tendo em vista os resultados do estudo, a avaliação da dor deve ser preocupação do enfermeiro, considerando que a identificação de sinais álgicos e sua caracterização, são ferramentas importantes para o cuidado ao RNPT. Por outro lado, a avaliação da dor caracteriza-se como um desafio no cuidado à criança apesar da certeza e das evidências científicas de que a identificação e o manejo da dor determinam um cuidado qualitativo. Ainda sob esta perspectiva é preciso que os profissionais de saúde valorizem os relatos das mães e os sinais por elas identificados que dizem respeito às condições clínicas do RN.

Faz-se importante afirmar que uma das formas de controlar a dor é a comunicação que se faz entre os RNPT e seus cuidadores (mães e profissionais). Portanto, reconhecer essa linguagem é uma das estratégias para o cuidado humanizado, qualificado e integral. Dessa forma, é preciso que profissionais e mães sejam capazes de identificar os sinais de dor utilizando a atenção e a sensibilidade para percebê-los.

As enfermeiras envolvidas no cuidado com RNPTs, assim como as mães dessas crianças, para intervirem efetivamente diante de um sinal de dor, devem estar aptas a reconhecer esses sinais emitidos pelo $\mathrm{RN}$, a fim de que contribuam para a diminuição ou ausência da dor de forma a proporcionar a recuperação e o desenvolvimento normal do RN.

\section{REFERÊNCIAS}

1 Balda RCX. Adultos são capazes de reconhecer a expressão facial de dor no recém-nascido? [dissertação]. São Paulo (SP): Universidade Federal de São Paulo/ Escola Paulista de Medicina;1999.

2 Guinsburg R, Kopelman BI, Almeida MFB, Miyoshi MHI. A dor no recém-nascido prematuro submetido a ventilação mecânica através de cânula traqueal. Jor. Pediat. 1994 Mar-Abr; 75 (3): 82-90.

3 Kopelman BI. Diagnóstico e tratamento em neonatologia. São Paulo (SP): Atheneu; 2004.

4 Chaud MN. O cotidiano na prática de enfermagem pediátrica. São Paulo (SP): Atheneu; 1999. 
5 Dias NS, Gaiva MAM. A dor no recém-nascido: percepção de profissionais de saúde de um hospital universitário. Rev. Paulista Enferm. 2002 Set; 21 (3): 234-9.

6 Guinsburg R. A Linguagem da dor no recém-nascido. São Paulo (SP): Sociedade Brasileira de Pediatria; 2000.

7 Guinsburg R. Avaliação e tratamento da dor no recémnascido. Jor. Pediat. 1999 Mai-Jun; 75 (3): 149-60.

8 Toniolli ACS, Pagliuca LMF. Percepção da dor em cegos: estratégias com grupos operativos. Texto Contexto Enferm. 2003 Abr-Jun; 12 (2): 201-9.

9 Reichert APS, Silva SLF, Oliveira JM. Dor no recémnascido: uma realidade a ser considerada. Rev. Nursing 2000 Ago; 3 (30): 28-30.

10 Grunau RVE, Craig KD. Pain expression in neonates: facial action and cry. Pain 1987 Dec; 31 (3): 395-410.
11 Aurimery GC, Grinsburg R, Balda RCX, Kopelman BI. $\mathrm{O}$ que os pediatras conhecem sobre avaliação e tratamento da dor no recém-nascido? J. Pediat 2003 Mai-Jun; 79 (3): 265-72.

12 Ministério da Saúde (BR). Manual do Curso de Atenção Humanizada ao RN de Baixo Peso: Método Mãe-Canguru. Brasília (DF): MS; 2002.

13 Pereira ALST, Guinsburg R, Almeida MFB, Monteiro AC, Santos AMN, Kopelman BI. Validade dos parâmetros comportamentais e fisiológicos para a avaliação da dor de recém-nascidos a termo [acesso em 2005 Out 10]. Disponível em: http//www.brazil/ pednews.org.br/junh99/A99012.htm

14 Burokas L. Factors affecting nurses: decisions to medicate pediatric patients after surgery. Heart Lung. 1985 Dec; 4 (2): 373-8.

\section{APÊNDICE 1}

\section{Instrumento de coleta de dados para as enfermeiras}

\section{IDENTIFICAÇÃO (Iniciais)}
Sexo F( ) M( )
Idade

2. Tempo de experiência profissional
()$<$ que 1 ano
( ) 1 a 3 anos
( ) 4 a 6 anos
( ) 7 a 9 anos
( ) mais de 9 anos

3. Há quanto tempo você trabalha na área de neonatologia?
$(\quad)<$ que 1 ano
( ) 1 a 3 anos
( ) 4 a 6 anos
( ) 7 a 9 anos
( ) mais de 9 anos

4. Em sua opinião as crianças prematuras sentem dor?
( ) Sim
( ) Não

Por quê?

\section{Só responder se a resposta anterior for positiva}

5. Quais as características de um recém-nascido prematuro com dor?
( ) chora
( ) recusa o peito
( ) boca estirada
( ) língua tensa
( ) outros. Quais:

( ) fica agitado

( ) boca aberta

( ) fronte saliente

( ) tremor do queixo

( ) fica muito quieto

( ) olhos espremidos

( ) sulco naso-labial aprofundado

( ) protusão da língua

6. Você acha importante tratar a dor no recém-nascido pré-termo?
( ) Sim
( ) Não

Por quê? 
7. Você conhece algum instrumento/escala para avaliação da dor no recém-nascido pré-termo?

( ) Sim Qual?

( ) Não

8. Aqui na UTI os recém-nascidos pré-termo recebem algum tipo de analgesia durante um procedimento doloroso?
( ) $\operatorname{Sim}$
( ) Não
( ) Às vezes

Caso a resposta tenha sido SIM ou ÀS VEZES. Em que casos ou procedimentos?

9. Olhe para este quadro e escolha a foto em que a face do recém-nascido é expressiva de dor
( ) Foto I
( ) Foto II
( ) Foto III
( ) Foto IV
( ) Foto V
( ) Foto VI

10. Por que você acha que a foto escolhida expressa dor?

\section{APÊNDICE 2}

\section{Instrumento de coleta de dados para as mães}

1. Este bebê é seu primeiro filho?

$\operatorname{Sim}($ ) Não ( ) Quantos filhos você já teve?

Caso a resposta seja negativa:

2. É seu primeiro filho prematuro?

$\operatorname{Sim}($ ) Não ( ) Quantos já teve?

3. Na sua opinião as crianças prematuras sentem dor?

$\operatorname{Sim}($ ) Não ( ) Porquê?

Se a resposta for Sim, responder as questões seguintes.

4. Quais as características de um recém-nascido prematuro com dor?
( ) chora
( ) fica agitado
( ) fica muito quieto
( ) recusa o peito
( ) boca aberta
( ) olhos espremidos
( ) boca estirada
( ) fronte saliente
( ) língua tensa
( ) tremor do queixo
( ) sulco naso-labial aprofundado
( ) outros. Quais:
( ) protusão da língua

5. Você acha importante tratar a dor no recém-nascido pré-termo?
( ) Sim
( ) Não
Porquê?

6. O que você faz quando você acredita que seu filho está com dor? 
7. Olhe para este quadro e escolha a foto em que a face do recém-nascido é expressiva de dor.
( ) Foto I
( ) Foto II
( ) Foto III
( ) Foto IV
( ) Foto V
( ) Foto VI

8. Por que você acha que a foto escolhida expressa dor?

\section{APÊNDICE 3}

\section{Quadro de fotos}

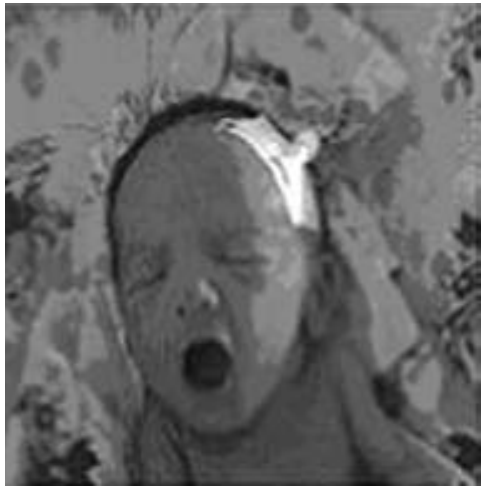

I

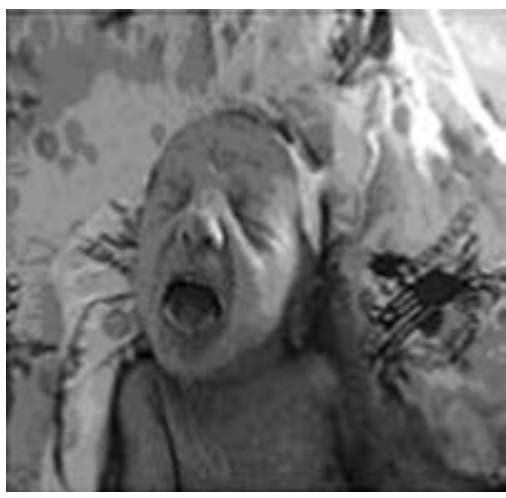

IV

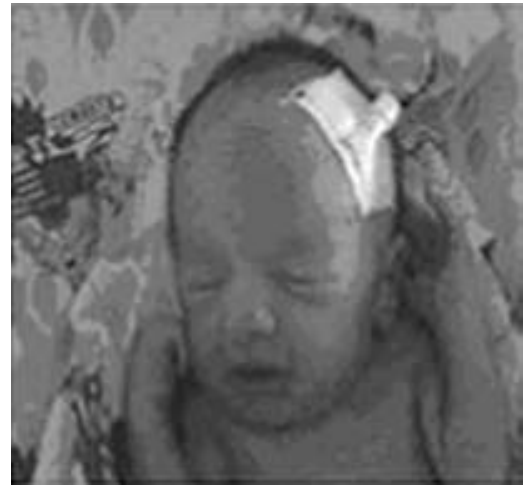

II

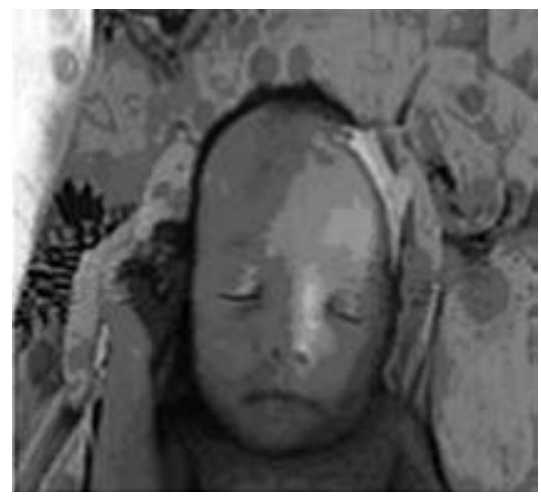

V

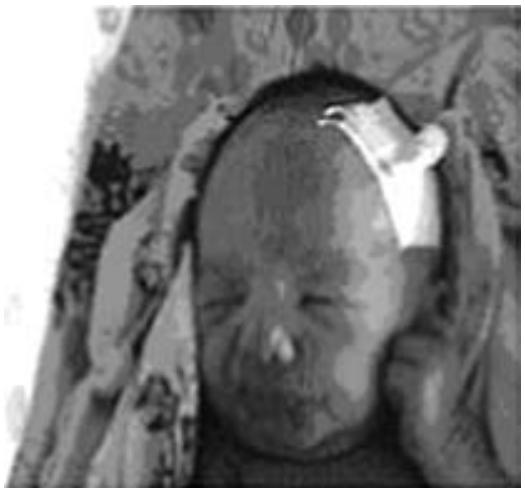

III

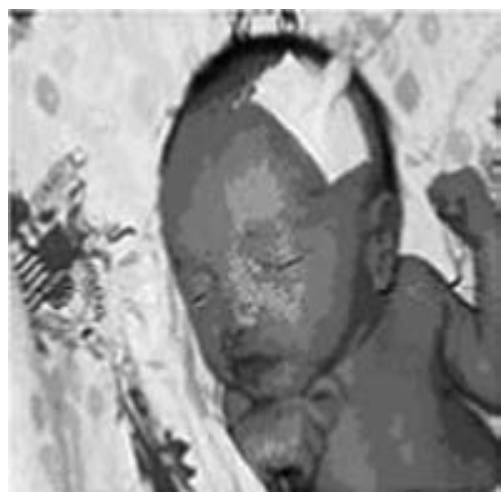

VI 